\title{
Forecast the exchange rate of the Iraqi dinar against the US dollar using different versions of GARCH models.
}

\author{
Muhammad H. Al-Sharoot \\ Omar M. Alramadhan \\ Department of Statistics , College of Administration and \\ Economics, University Of AL-Qadisiyah-IRAQ \\ malsharood@gmail.com \\ omar.muhy13@gmail.com
}

Recived : 11812018

Revised : $16 \backslash 812018$

Accepted : 219\2018

Available online : $26 / 9 / 2018$

DOI: $10.29304 / j q c m .2018 .10 .3 .442$

\begin{abstract}
There are many time series that are characterized by large variability, which makes them suffer from the problem of heterogeneity of contrast clearly, Where the time series analysis requires the homogeneity of variance for this purpose was the study and review of some important models used in dealing with the time series heterogeneous in contrast, a GARCH, ARMA-GARCH,TGARCH, EGACH , When the distribution of errors follows the normal distribution which was discovered by Engle since 1982, The aim of this study was to forecast . This study aimed at forecasting the exchange rates of the Iraqi dinar against the US dollar for the period from 2010 to 2018 through an analysis of fluctuations in the exchange rate series. The application of the studied data showed that the best model for predicting volatility is ARMA (0-1) -GARCH 2.1) based on some criteria for selecting the AIC, SIC, H-QIC and the significance of the estimated model parameters.
\end{abstract}

Keywords: heterogeneity of variance, yield chain, GARCH, EGARCH, TGARCH, ARMA-GARCH, AIC, SIC, H-QIC 


\section{Review of Literature}

The first model was proposed by the world (Robert F. Engle) in 1982 when he studied the variability of monetary inflation in the UK. It has been found that the proposed model is more accurate in prediction.

In 1986, Bollerslev presented a more generalized model called Generalized Autoregressive Conditional Heteroscedasticity, which became known as the GARCH model. It includes the conditional variation in the model when the error follows normal distribution as well. Determine the terms of the stability and self-correlation of this model.

In 1987, the researchers (Engle, RF) proposed the GARCH-in-Mean (GARCH-M) model, since this model adds the term heteroscedasticity to the arithmetic mean equation, which allows the average revenue to be defined as a linear function of time.

In 1991 Nelson presented the EGARCH model with an error following the distribution of the general error and used it to estimate the exceptional risk in the weighted value index market for 1962-1978 and concluded that the EGARCH model was better than the GARCH model.

In 1994, Zakoian first proposed the Threshold GARCH (TGARCH) model, which allows the asymmetric effects of positive and negative shocks to fluctuate and enables it to be applied to the pattern of volatility in stock returns in the French market.

In 2008, the researcher, Abdullah Suhail star, the study included models (ARCH and GARCH) and the use of method (Conditional MLE) to estimate and then studied the predictions of subsequent views you and use the style simulation to generate data and calculate a general formula to calculate the torque coefficient splaying models GARCH and ARCH from the lower grades.

In 2011, the researcher Mohammed, Mohamed Jassim, studied the use of GARCH models to predict the Saudi stock market index. He studied the process of diagnosis and estimation of the appropriate model and found that the best model for data representation is GARCH $(1,1) \mathrm{t}$ distribution errors.

\section{Introduction:}

Some researchers focus on time series topics because they are important in studying the behavior of different phenomena over specific time periods through their analysis and interpretation, The topics of the time series include many areas (medical, environmental, economic, etc.) ,The definition of the time series (it is a series of observations that are arranged according to time of occurrence) There are two types, the first is Discrete Time Series and the second is the continuous time series, The aim of the time series analysis is to obtain an accurate description of the features of the phenomenon from which the time series is produced, and to construct a model to explain the behavior of that phenomenon, and predict future observations of the phenomenon studied based on what happens in the past. The most important models applied to time series data are the ARMA models used in many different fields. To be able to use the ARMA model, there must be three conditions for the random error of the model:

$$
\begin{aligned}
& \text { i) } E\left(\varepsilon_{t}\right)=0 \\
& \text { ii) } V\left(\varepsilon_{t}\right)=E\left(\varepsilon_{t}^{2}\right)=\sigma^{2} \\
& \text { iii) } E\left(\varepsilon_{t} \varepsilon_{s}\right)=0 \text { for } t \neq s
\end{aligned}
$$

In the event of a breach of those conditions for the existence of a particular factor may be externally or an emergency on time series must look for other models can adapt to those factors that led to the existence of differences in terms of this time series, and in particular in the time series on financial transactions.

\section{Problem Search:}

The problem for the search in the presence of fluctuations in the prices of a series of Iraqi dinar against the US dollar, which led to the instability of the US dollar and thus the use of regular ARMA models would get irrational future predictions. The plans based on these results are therefore useless.

\section{The aim:}

The aim is to build the best model for forecasting the Iraqi dinar price series versus the US dollar daily for the period from 2010 to 2018 by applying a number of different models that are used to predict in time series of volatility, including GARCH model, TGARCH model, ARMA-GARCH model, and EGARCH model. 
Muhammad .H/ Omar .M

\section{Autoregressive Conditional}

Heteroscedasticity models $\left(\mathrm{ARCH}_{(\mathbf{p})}\right):^{[5][4]}$ It was the first model proposed by Robert Engle in 1982. The ARCH model is a return series with a conditional average and a conditional variation. The conditional mean of the return series $\mu_{t}$ is constant, the conditional variance of the return series is in the form of a model that contains an error limit and a non-stability equation, the equations of the ARCH model are as follows.

$\mathrm{y}_{\mathrm{t}}=\mu+\mathrm{x}_{\mathrm{t}}$

$\mathrm{x}_{\mathrm{t}}=\sigma_{\mathrm{t}} * \varepsilon_{\mathrm{t}} \quad \ldots \ldots(2) \quad, \varepsilon_{\mathrm{t}} \approx \operatorname{iidN}(0,1 \quad$ and $\sigma_{\mathrm{t}}^{2}=\Omega+\alpha_{1} \mathrm{x}_{\mathrm{t}-1}^{2}+\alpha_{2} \mathrm{x}_{\mathrm{t}-2}^{2}+\cdots+\alpha_{\mathrm{j}} \mathrm{x}_{\mathrm{t}-\mathrm{p}}^{2} \cdots \cdots$

(3)

Where $\sigma_{t}^{2}$ is the equation of volatility, which can be written in the formula below.

$\sigma_{t}^{2}=\Omega+\sum_{j=1}^{p} \alpha_{j} x_{t-j}^{2}$

Whereas $\Omega>0, \quad \alpha_{j} \geq 0, \quad j=1,2, \ldots . ., p$ and, $\Omega, \alpha_{\mathbf{j}}$, represent the parameters of the model. The process is in the case of stability if and only if the total parameters of the Autoregressive are positive and less than one.

\section{Generalized Autoregressive} Conditional Heteroscedasticity Model $\left(\operatorname{GARCH}_{(\mathbf{p}, \mathbf{q})}\right):^{[5][4]}$

GARCH models $(\mathrm{p} \geq 1)$ and $(\mathrm{q} \geq 1)$ can be defined as follows:

$\mathbf{y}_{\mathrm{t}}=\mu+\mathrm{x}_{\mathrm{t}} \quad$ and,$\varepsilon_{\mathrm{t}} \approx \operatorname{iidN}(0,1)$

$\mathrm{x}_{\mathrm{t}}=\sigma_{\mathrm{t}} * \varepsilon_{\mathrm{t}}$

$\sigma_{\mathrm{t}}^{2}=\Omega+\alpha_{1} \mathrm{x}_{\mathrm{t}-1}^{2}+\alpha_{2} \mathrm{x}_{\mathrm{t}-2}^{2}+\cdots+\alpha_{\mathrm{p}} \mathrm{x}_{\mathrm{t}-\mathrm{p}}^{2}+$

$\beta_{1} \sigma_{t-1}^{2}+\beta_{2} \sigma_{t-2}^{2}+\cdots+\beta q \sigma_{t-q}^{2} \cdots . .(5)$

As the $y_{t}$ series represents a stable return series and uncorrelated

and $\mu$ represents the average of the stable return series

And that they are independent $\varepsilon_{\mathrm{t}}$ series and similar distribution (independent identically distribution) and keep track of the standard normal distribution with mean 0 and variance 1 .

And $\sigma_{\mathrm{t}}^{2}$ is the equation of volatility, which can be written in the formula below.

$\sigma_{\mathrm{t}}^{2}=\Omega+\sum_{\mathrm{j}=1}^{\mathrm{p}} \alpha_{\mathrm{j}} \mathrm{x}_{\mathrm{t}-\mathrm{j}}^{2}+\sum_{\mathrm{i}=1}^{\mathrm{q}} \beta_{\mathrm{i}} \sigma_{\mathrm{t}-\mathrm{i}}^{2}$

whereas.

$\Omega>0, \quad \alpha_{j} \geq 0, \quad j=1,2, \ldots ., p, \quad \beta_{i} \geq 0, \quad i$ $=1,2, \ldots \ldots, \mathrm{q}$

And, $\Omega, \alpha j, \beta i$ represent the parameters of the model.

\section{Exponential Generalized Autoregressive Conditional Heteroscedastic Models (EGARCH) [1][4]}

This model suggested by Nelson in (1991) and on the contrary, the classic model GARCH which assumes symmetry oscillations around the shock. As well as the positive constraint imposed on parameters, Because the EGARCH model describes the relationship between the previous values of the random error and the conditional variation logarithm, with no restrictions on transactions that ensure that there are no negative effects of conditional variation, which allows avoiding positive transaction constraints $\left(\boldsymbol{\beta}_{\mathbf{j}} \& \boldsymbol{\alpha}_{\mathbf{i}}\right)$, As follows:

Let us have the EGARCH model of the class ( $p$, q) $(p \geq 1) \&(q \geq 1)$. Therefore, this model can be written as follows:

$$
\begin{aligned}
& \mathbf{y}_{\mathbf{t}}=\boldsymbol{\mu}+\mathbf{x}_{\mathbf{t}} \\
& \mathrm{x}_{\mathrm{t}}=\sigma_{\mathrm{t}} \varepsilon_{\mathrm{t}} \quad \varepsilon_{\mathrm{t}} \sim \text { iid N }(0,1) \\
& \ln \left(\sigma_{\mathrm{t}}^{2}\right)=\Omega+\sum_{\mathrm{j}=1}^{\mathrm{q}} \beta_{\mathrm{j}} \ln \left(\sigma_{\mathrm{t}-\mathrm{j}}^{2}\right)+\sum_{i=1}^{p} \alpha_{i}\left\{\left|\frac{x_{t-i}}{\sigma_{t-i}}\right|-\sqrt{\frac{2}{\pi}}\right\} \\
& +\lambda_{i} \frac{x_{t-i}}{\sigma_{t-i}}
\end{aligned}
$$

or

$\log \left(\sigma_{\mathrm{t}}^{2}\right)=\Omega+\sum_{i=1}^{p} \alpha_{i} g\left(Z_{t}\right)+\sum_{\mathrm{j}=1}^{\mathrm{q}} \beta_{\mathrm{j}} \log \left(\sigma_{\mathrm{t}-\mathrm{j}}^{2}\right)$

whereas

$$
\begin{aligned}
& \mathbf{g}\left(\mathbf{Z}_{\mathbf{t}}\right)=\boldsymbol{\theta} \mathbf{Z}_{\mathbf{t}}+?\left(\left|\mathbf{Z}_{\mathbf{t}}\right|-\mathbf{E}\left(\left|\mathbf{Z}_{\mathbf{t}}\right|\right) \quad \& \quad \mathbf{Z}_{\mathbf{t}}=\mathbf{x}_{\mathbf{t}} / \boldsymbol{\sigma}_{\mathbf{t}}\right. \\
& \mathbf{E}\left(\mathbf{x}_{\mathrm{t}} / \boldsymbol{\sigma}_{\mathbf{t}}\right)=\mathbf{E}\left\{\frac{\left|\mathbf{x}_{\mathbf{t}-\mathrm{i}}\right|}{\boldsymbol{\sigma}_{\mathrm{t}-\mathrm{i}}}\right\}=\sqrt{\frac{2}{\pi}} \\
& (\Omega)(\&) \mathrm{j}=1,2, \ldots, \mathrm{q} \cdot \mathrm{i}=1,2, \ldots, \mathrm{p} \quad, \beta_{\mathrm{j}} \quad \alpha_{\mathrm{i}}
\end{aligned}
$$

Represent the model parameters is not required to be positive, while $Z_{t}$ may be a normal standard variable, or come from the generalized error distribution, and that the equation $g\left(Z_{t}\right)$ allows the signal size $Z_{t}$ to be discrete effects from fluctuations, , And that the $\mathrm{z}_{\mathrm{t}}$ limits are positive if the $g\left(z_{t}\right)$ is linear with parameters $(\boldsymbol{\theta}+\lambda)$ If $z_{t}$ is negative, the $g\left(z_{t}\right)$ is linearized by parameters $(\boldsymbol{\theta}$ $\lambda$ ) This situation allows for asymmetry on the rise and fall in the share price, which in turn is very useful, especially in the context of bond pricing. 


\section{7. (Threshold Generalized}

\section{Autoregressive Conditional}

\section{Heteroscedastic Models) (TGARCH)} [11],[1]

The idea behind the TGARCH model is that it is better to capture negative shocks because they have a greater impact on fluctuations than positive shocks. To be able to capture these movements, a model must be studied that allows this model to determine the conditional standard deviation by referring to the previous lag. Allow models (GARCH) with threshold ((TGARCH access to different functions depending on fluctuations in this signal and shock value.

The models can be defined (TGARCH) class ( $p$, q) $(P \geq 1) \&(q \geq 1)$ the following formula:

$\mathbf{y}_{\mathbf{t}}=\boldsymbol{\mu}+\mathbf{x}_{\mathrm{t}}$

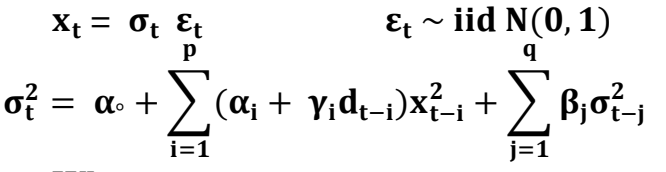

Where

$\mathbf{d}_{\mathrm{t}-\mathrm{i}}=$

$\left\{\begin{array}{llll}\mathbf{1} & \text { if } & \mathbf{x}_{\mathrm{t}-\mathrm{i}}<0 & \text { bad news } \\ 0 & \text { if } & \mathbf{x}_{\mathrm{t}-\mathrm{i}} \geq 0 & \operatorname{good} \text { news }\end{array}\right.$

As the $\left(\alpha_{0}>0\right)$ and $(i=1,2, \ldots, p, j=1,2, \ldots, q$ for $\boldsymbol{\gamma}_{\mathbf{i}} \geq 0, \quad \beta_{j} \geq 0, \alpha_{i} \geq 0$ ) represent the model parameters (Parameters), $\left(\mathrm{d}_{t i}\right)$ variable placebo (Dummy variable).

Known as $\gamma$ or variable balance financial leverage. In this model, good news $\left(\mathrm{x}_{t-i}>0\right)$ and bad news $\left(\mathrm{x}_{t-i}<0\right)$ have a different effect on conditional variation. Good news has an effect on $\alpha_{i}$,

While the bad news affecting $\alpha \mathrm{i}$ and $\gamma \mathrm{i}$. Thus, if it is large and positive $\gamma$, the negative shocks have a greater impact on $\sigma_{t}^{2}$ of positive shocks and that the abolition of positive transaction restrictions allow for taking into account the phenomenon of symmetry or asymmetry that characterize the fluctuations, and thus become a shock $\left(\mathrm{x}_{t-i}\right)$ The conditional variation depends on both volume and shock signal.

\section{Model ARMA (n, m) - GARCH (p, q) ${ }^{[4],[6]}$ :}

We know that the ARMA (n, m) models have a conditional modulus of previous information that is not constant and the conditional variance of a fixed error. The GARCH (p, q) models have a conditional average of the previous information constant and the conditional variance of the error is not constant. If both conditional and conditional conditions depend on the past (not fixed), then the two models are combined with a model known as ARMA (n, m) - GARCH (p, q) where it becomes as follows:

$\mathrm{y}_{\mathrm{t}}=\emptyset_{0}+\sum_{\mathrm{i}=1}^{\mathrm{n}} \emptyset_{\mathrm{i}} \mathrm{y}_{\mathrm{t}-\mathrm{i}}+\mathrm{x}_{\mathrm{t}}-\sum_{\mathrm{j}=1}^{\mathrm{m}}$ $_{\mathrm{j}} \mathrm{x}_{\mathrm{t}-\mathrm{j}}$

$\mathrm{x}_{\mathrm{t}}=\sigma_{\mathrm{t}} \varepsilon_{\mathrm{t}} \quad, \quad \varepsilon_{\mathrm{t}} / \mathrm{F}_{\mathrm{t}-1} \sim \mathrm{iid}(\mathbf{0}, \mathbf{1})$

$\sigma_{t}^{2}=\Omega+\sum_{i=1}^{p} \alpha_{i} x_{t-i}^{2}+\sum_{j=1}^{q} \beta_{j} \sigma_{t-j}^{2}$

And $y_{t}$ represents ARMA model $(n, m)$, except that the error limit (white noise) $x_{t}$ not be independent, but symmetric distribution, which is not linked to the process, so has the same function properties of autocorrelation (ACF) process independent error, as well as the $y_{t}$ possesses the same function autocorrelation model ARMA (n, m) normal (symmetric error and independent distribution). Also, $x_{t}^{2}$ series will be subject to the model ARMA $(p, q)$ error is weak.

\section{Augmented Dickey-Fuller Test}

\section{[5][8]:}

Augmented Dickey Fuller test uses (ADF) to detect the presence of the root of the unit in univariate test any time series whether stable series or not, The ADF test has a regression in the first difference in the string against the string with the time offset (p).

Using the following equation:

$\Delta \mathbf{y}_{\mathbf{t}}=\mu+\lambda_{\mathbf{t}}+\emptyset \mathbf{y}_{\mathbf{t}-\mathbf{1}}+\sum_{\mathbf{j}=\mathbf{1}}^{\mathbf{k}} \boldsymbol{\delta}_{\mathbf{j}} \Delta \mathbf{y}_{\mathbf{t}-\mathbf{j}}+\mathbf{x}_{\mathbf{t}}$

As the $y_{t}$ represents the time series to be tested, $k$ number of offsets time, $\Delta$ represents the first differences in a series of return, $x_{t}$ represents an error $x_{t} \sim$ iid $\left(0, \sigma^{2}\right)$, and $\left(\mu, \lambda, \boldsymbol{\delta}_{\mathbf{j}}, \emptyset\right)$ Symbolizes the parameters of its appreciation. The hypothesis can be tested

$\mathbf{H}_{\circ}: \emptyset=\mathbf{0}$ Series yield has unit root (Series yield is unstable)

$\mathbf{H}_{\mathbf{1}}: \emptyset<\mathbf{0}$ A series yield does not has a unit root (Series yield is stable)

Using statistics:

$$
\boldsymbol{\tau}=\frac{\widehat{\emptyset}}{\operatorname{se}(\widehat{\varnothing})}
$$

The null hypothesis is rejected if the t-statistic value is greater than the statistical value of t-statistic and vice versa. 


\section{Ljung - Box Test ${ }^{[10][7]}$}

The researchers (Ljung \& Box) proposed this test in 1978, To test random errors of the time series by calculating the autocorrelation coefficients of a series of displacements, the following hypothesis is tested:

$H_{\circ}: \rho_{1}=\rho_{2}=\cdots=\rho_{k} \cdots=\rho_{m}=0$

; $\mathbf{k}=1,2, \ldots . \mathbf{m}$

$H_{1}: \rho_{k} \neq 0$ for some values of $k$

Using statistics:

$\mathbf{Q}_{(\mathbf{m})}=\mathbf{n}(\mathbf{n}+2) \sum_{\mathbf{k}=1}^{\mathbf{m}} \frac{\widehat{\boldsymbol{\rho}}_{\mathbf{k}}^{2}}{\mathbf{n}-\mathbf{k}} \sim \chi_{\mathbf{m}-\mathbf{p}}^{2}$

And that each of:

$\mathrm{n}$ : Represents the sample size (number of views of the time series).

$\mathrm{m}$ : It represents the number of shifts to self-link. $\mathrm{p}$ : Number of parameters estimated in the model $\widehat{\boldsymbol{\rho}}_{\mathbf{k}}^{2}$ : Represent the capabilities of the selfcorrelation boxes of the model's residual series. then for string $\mathrm{x}_{\mathrm{t}}=\mathrm{y}_{\mathrm{t}}-\mu$ and $x_{t}^{2}$.

If $p$-value $\geq 0.05$ means not rejecting the hypothesis $\mathrm{H}_{0}$, the errors $\mathrm{x}_{\mathrm{t}}=\mathrm{y}_{\mathrm{t}}-\mu$ are random (Identically Independent Distribution) and there is (no effect ARCH) or (heteroscedasticity), and vice versa.

\section{Lagrange Multiplier (ARCH - Test $)^{[7][8]}$}

It was proposed by Engle in 1982 and is used to determine whether the errors follow the $\mathrm{ARCH}$ process or not, which is based on the estimation of the equation under study in the form of the smallest squares and then the estimation of errors and squares for previous periods. This means that we estimate the following equation: $\mathbf{x}_{\mathrm{t}}^{2}=$

$\Omega+\alpha_{1} x_{t-1}^{2}+\alpha_{2} x_{t-2}^{2}+\ldots+\alpha_{p} x_{t-p}^{2}$

$\mathbf{x}_{\mathbf{t}}=\mathbf{y}_{\mathbf{t}}-\boldsymbol{\mu}$, To test $(\mathrm{ARCH}(\mathrm{P}))$ we calculate the product of the coefficient of determination resulting from this estimate used the sample size of any amount $\mathbf{T} \mathbf{R}^{2}$, Which is followed by $\chi_{\mathrm{p}}^{2}$, Of the degree of freedom (p) under the premise of the nuisance that the errors are homogeneous (Conditional Homoscedasticity) The small values of $\mathrm{R}^{2}$ mean that the errors of the previous periods do not affect the current error and therefore there is no trace of the ARCH effect. archtest $=\mathbf{T} \widehat{\mathbf{R}}^{2} \sim \chi_{(\mathbf{P})}^{2}$
12. Estimation ${ }^{[5]}:-$

Can be used Maximum likelihood Method To estimate GARCH parameters ( $p, q)$ as follows:

$f\left(x_{t} / F_{t-1}\right)=\frac{1}{\sqrt{2 \pi \sigma_{t}^{2}}} \exp \left(-\frac{1}{2} \frac{x_{t}^{2}}{\sigma_{t}^{2}}\right)$

The natural logarithm (L) function of vector parameters $\boldsymbol{\vartheta}=\left(\boldsymbol{\Omega}_{\circ}, \boldsymbol{\alpha}_{\mathbf{1}}, \ldots, \boldsymbol{\alpha}_{\mathrm{p}}, \boldsymbol{\beta}_{\mathbf{1}}, \ldots, \boldsymbol{\beta}_{\mathbf{q}}\right)^{\prime}$

We can write as follows:

$\mathbf{L}(\boldsymbol{\vartheta})=\sum_{\mathbf{t}=\mathbf{1}}^{\mathbf{n}} \mathbf{I}_{\mathbf{t}}(\boldsymbol{\vartheta}) \ldots \ldots$

the conditional logarithm of the parameter vector $\boldsymbol{\vartheta}$ is

$$
\begin{aligned}
I_{t}(\boldsymbol{\vartheta})= & \operatorname{Ln} \mathbf{f}\left(\mathbf{x}_{\mathrm{t}} / \mathbf{F}_{\mathrm{t}-1}\right) \\
\mathbf{I}_{\mathrm{t}}(\boldsymbol{\vartheta})= & \frac{1}{2} \operatorname{Ln}(2 \pi)-\frac{1}{2} \operatorname{Ln}\left(\sigma_{\mathrm{t}}^{2}\right) \\
& -\frac{1}{2}\left(\frac{x_{t}^{2}}{\sigma_{\mathrm{t}}^{2}}\right) \quad \ldots
\end{aligned}
$$

The following derivatives are calculated:

$\frac{\partial \mathbf{I}_{\mathbf{t}}}{\partial \boldsymbol{\vartheta}}=\frac{\partial \mathbf{I}_{\mathbf{t}}}{\partial \boldsymbol{\sigma}_{\mathrm{t}}^{2}} \frac{\partial \boldsymbol{\sigma}_{\mathbf{t}}^{2}}{\partial \boldsymbol{\vartheta}}$

The logarithm of the conditional probability density function is derived for the variable $y_{t}$ for $\Omega, \alpha_{\mathrm{i}}, \beta_{\mathrm{j}}$

\section{Model selection criteria: ${ }^{[10]}$}

To choose the best model among those proposed models for assessment and prediction of the studied data, developed choice of model data, which ideally criteria and selection of the most common model standards are:

\section{I - Akaikes Information criterion (AIC) ${ }^{[10][5]}$}

Akaike (1974) presented a standard of information known as (AIC) When the time series models in $(\mathrm{L})$ are reconciled with the parameters of the time series data under consideration and to assess the suitability of those models, the AIC is calculated for each model and the model that gives the lowest value is selected. The AIC formula can be written as follows:

$A I C=n \ln \left(\widehat{\sigma}_{e}^{2}\right)+2 L$

n: represents the sample size.

$\hat{\sigma}_{e}^{2}:$ The variance of the model is calculated as follows:

$\widehat{\sigma}_{e}^{2}=\frac{1}{n-L} \sum_{t=1}^{n}\left(y_{t}-\hat{y}_{t}\right)^{2}$

$\mathrm{L}:$ is the rank of the model. 
II - Schwarz Information criterion (SIC): [7][5]

In 1978, Schwarz introduced a new standard known as the Schwarz standard.

$S I C=n \ln \left(\widehat{\sigma}_{e}^{2}\right)+L \ln (n)$

$\mathrm{n}$ : represents the sample size.

$\hat{\sigma}_{e}^{2}:$ The variance of the model is calculated as follows:

$\widehat{\sigma}_{e}^{2}=\frac{1}{n-L} \sum_{t=1}^{n}\left(y_{t}-\hat{y}_{t}\right)^{2}$

$\mathrm{L}$ : is the rank of the model.

This criterion addressed the problem of overestimation in the AIC standard, And make the Penalty of the additional parameters stronger than the penalty in the AIC standard). The penalty for this criterion is $L(I n) n$. One of the advantages of the SIC is that it estimates the rank of a model consistently that $\mathrm{p}, \mathrm{q}$ is less or equal $\left(\mathrm{p}_{\max }, \mathrm{q}_{\max }\right.$, respectively). It is stated that with reference to the chosen $\mathrm{AIC}$ or $\mathrm{SIC}, \widehat{P}(\mathrm{SIC}) \leq \widehat{\mathrm{P}}(\mathrm{AIC})$ Remain constant even in cases of small samples. Therefore, the use of SIC results leads us to models with minimal parameters.

\section{iii- H-Q Hannan- Quinn Criterion: ${ }^{[5][7]}$}

The researchers Quinn and Hannan (1979) proposed a new criterion for determining the rank of the studied model called Hannan-Quinn Criterion (H-Q (h)) and its mathematical formula:

$$
\begin{gathered}
H-Q=\ln \widehat{\sigma}_{e}^{2}+2 L C \ln \left(\frac{\ln (n)}{n}\right), \quad C \\
>2 \quad \ldots(22)
\end{gathered}
$$

As the second limit above decreases as quickly as possible at the stability of the rank due to the repeated logarithm.

\section{Forecasting:}

Prediction is one of the most important objectives of model construction in time series. It represents the last stage of time series analysis that can't be accessed without passing all tests and diagnostic tests to validate the model used in prediction. The following is a forecast prediction of the GARCH model. In the same way for all models (EGARCH, GARCH-M)
The prediction of the GARCH model $(\mathrm{p}, \mathrm{q})$ ) (where $\mathrm{p}=1, \mathrm{q}=1$, GARCH ${ }_{(\mathbf{1 . 1})}$ ) is as follows: $\sigma_{t}^{2}=E\left(x_{t}^{2} \mid I_{t}\right)=\widehat{\Omega}+\widehat{\alpha}_{1} x^{2}{ }_{t-1}+\widehat{\beta}_{1} \sigma^{2}{ }_{t-1}$ Predicting one future value

$\sigma^{2}{ }_{t+1}=E\left(x^{2}{ }_{t+1} \mid I_{t}\right)=\widehat{\Omega}+\widehat{\alpha}_{1} E\left(x^{2}{ }_{t} \mid I_{t}\right)+$ $\widehat{\boldsymbol{\beta}}_{\mathbf{1}} \boldsymbol{\sigma}^{2}{ }_{\mathbf{t}}$

$\boldsymbol{\sigma}^{2}{ }_{t+1}=\widehat{\Omega}+\widehat{\alpha}_{1} \sigma_{t}^{2}+\widehat{\beta}_{1} \sigma^{2}{ }_{t}$

$\boldsymbol{\sigma}^{2}{ }_{\mathbf{t}+\mathbf{1}}=\widehat{\boldsymbol{\Omega}}+\left(\widehat{\boldsymbol{\alpha}}_{\mathbf{1}}+\widehat{\boldsymbol{\beta}}_{\mathbf{1}}\right) \boldsymbol{\sigma}^{2}{ }_{\mathbf{t}}$

Prediction of value $\mathrm{L}$

$\sigma^{2}{ }_{t+l}=E\left(x_{t+l}^{2} \mid I_{t}\right)=\widehat{\Omega}+\widehat{\alpha}_{1} E\left(x_{t+l-1}^{2} \mid I_{t}\right)+$

$\widehat{\boldsymbol{\beta}}_{\mathbf{1}} \mathbf{E}\left(\sigma_{\mathbf{t}+l-\mathbf{1}}^{2} \mid \mathbf{I}_{\mathbf{t}}\right)$

$\widehat{\boldsymbol{\Omega}}+\widehat{\boldsymbol{\alpha}}_{\mathbf{1}}{\sigma^{2}}_{\boldsymbol{t}+l-1}+\widehat{\boldsymbol{\beta}}_{\mathbf{1}} \boldsymbol{\sigma}_{\mathbf{t}+l-1}^{2}=\sigma_{\mathbf{t}+\boldsymbol{l}}^{2}$

$\boldsymbol{\sigma}_{\mathbf{t}+\boldsymbol{l}}^{2}=\widehat{\boldsymbol{\Omega}}+\left(\widehat{\boldsymbol{\alpha}}_{\mathbf{1}}+\widehat{\boldsymbol{\beta}}_{\mathbf{1}}\right) \boldsymbol{\sigma}_{\mathbf{t}+\boldsymbol{l}-\mathbf{1}}^{2}$

Thus, the general formula for predicting

GARCH (p, q) models is as follows:

$\sigma^{2}{ }_{t+l}=\widehat{\Omega}+\sum_{i=1}^{p} \widehat{\alpha}_{i} \sigma_{t+l-i}^{2}+\sum_{j=1}^{q} \widehat{\beta}_{j} \sigma_{t+l-j}^{2}$

\section{Forecasting accuracy measures:}

to measure prediction accuracy developed standards are called the chosen model prediction accuracy standards is the most important.

\section{i-: Root Mean Square Error (RMSE) :- ${ }^{[3][11]}$}

This criterion is defined as the square root of the squared difference between both the actual variance and the prediction variability $\sigma_{t}^{2}$, Due to the absence of significant real variation, the time series observations were used $x_{t}^{2}$.

Thus, the RMSE formula is given as follows:

$$
\begin{array}{r}
\text { RMSE }=\sqrt{\frac{1}{n} \sum_{t=1}^{n}\left(x_{t}^{2}-\widehat{\sigma^{2}}\right)^{2}} ; t \\
=1,2, \ldots, n \quad \ldots .
\end{array}
$$

whereas

$\widehat{\sigma^{2}}{ }_{t}$ represents the estimated variance.

$x_{t}^{2}$ represents the actual contrast.

ii-: Mean Absolute Error (MAE) ${ }^{[3][10]}$

This standard is defined as the absolute difference between actual and forecast variability, and the formula of the standard is given as follows:

$$
M A E=\frac{1}{T} \sum_{t=1}^{\mathrm{T}}\left|x_{t}^{2}-{\widehat{\sigma^{2}}}_{t}\right|
$$


Muhammad .H/ Omar .M

\section{Applied side}

The exchange rate series of the Iraqi dinar against the US dollar was analyzed for the period from 9/4/2010 to $10 / 5-2018$ on a daily basis except for non-trading days, and the views were 2864 daily. $Y_{t}$ returns were calculated using the natural logarithm of the data according to the following equation:

$\mathbf{y}_{\mathrm{t}}=\ln \left(\mathbf{P}_{\mathrm{t}}\right)-\ln \left(\mathbf{P}_{(\mathrm{t}-1)}\right)$

whereas:

$\mathrm{P}_{\mathrm{t}}$ : is the exchange rate of the Iraqi dinar against the US dollar at the period t.

$\mathrm{P}_{(\mathrm{t}-1)}$ : The exchange rate of the Iraqi dinar against the US dollar at the period $\mathrm{t}-1$.

Figure (1) shows the format of the time series of the Iraqi dinar against the

dollar.

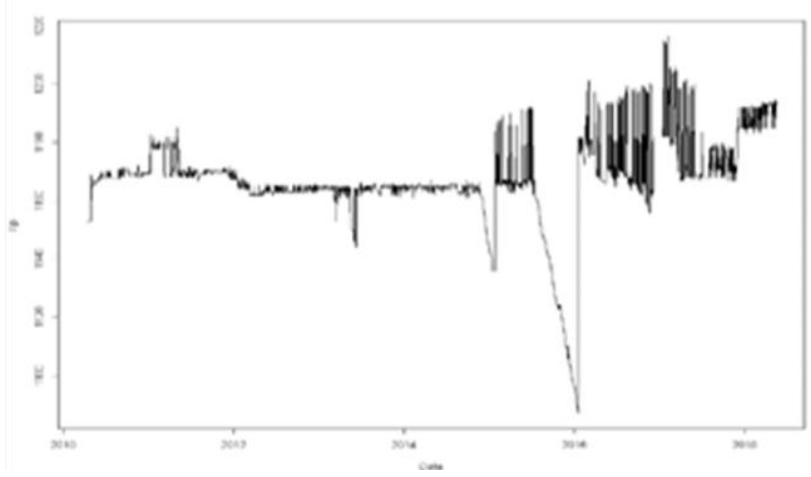

Note from Figure (1) that the time series of the dinar exchange rate against the US dollar is unstable and has high volatility, indicating that there are fluctuations in the variance.

Dicky Fuller Developer's Series Test Exchange Rates for Iraqi Dinar against US Dollar:

For the purpose of detecting the stability of the time series of the exchange rate of the Iraqi dinar daily was calculated test Dicky Fuller developer and the test results as shown in Table (1)
Table (1) shows the developer's Dicky Fuller test to test the stability of the time series

\begin{tabular}{|c|c|c|}
\hline \multirow{2}{*}{\multicolumn{3}{|c|}{$\begin{array}{l}\text { Augmented Dickey-F } \\
\text { alternative: stationary }\end{array}$}} \\
\hline & & \\
\hline $\begin{array}{l}\text { Type 1: no } \\
\text { drift no } \\
\text { trend }\end{array}$ & $\begin{array}{l}\text { Type 2: } \\
\text { with drift } \\
\text { no trend }\end{array}$ & $\begin{array}{l}\text { Type 3: } \\
\text { with drift } \\
\text { and trend }\end{array}$ \\
\hline $\begin{array}{l}\text { Lag ADF } \\
\text { p.value }\end{array}$ & $\begin{array}{l}\text { Lag } \\
\text { ADF } \\
\text { p.value }\end{array}$ & $\begin{array}{l}\text { Lag } \\
\text { ADF } \\
\text { p.value }\end{array}$ \\
\hline $\begin{array}{cc}{[1,]} & 0 \\
-0.0574 \\
0.627\end{array}$ & $\begin{array}{l}{[1,] \quad 0} \\
{ }^{12.72} \\
0.01\end{array}$ & 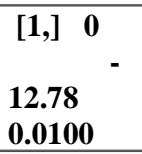 \\
\hline $\begin{array}{l}{[2,1} \\
0.0658 \\
0.663\end{array}$ & $\begin{array}{r}{[2,] \quad 1} \\
-8.05 \\
0.01\end{array}$ & $\begin{array}{l}{[2,] \quad 1} \\
8.09 \\
0.0100\end{array}$ \\
\hline $\begin{array}{l}{[3,] 2} \\
0.1420 \\
0.685\end{array}$ & $\begin{array}{r}{[3,] 2} \\
-6.17 \\
0.01\end{array}$ & $\begin{array}{ll}{[3,]} & 2 \\
& - \\
6.21 & \\
0.0100\end{array}$ \\
\hline $\begin{array}{l}{[4,] 3} \\
0.1754 \\
0.694\end{array}$ & $\begin{array}{r}{[4,]} \\
3 \\
-5.52 \\
0.01\end{array}$ & $\begin{array}{ll}4,] & 3 \\
& - \\
5.55 & \\
0.0100\end{array}$ \\
\hline $\begin{array}{l}{\left[5,{ }^{4} 4\right.} \\
0.2259 \\
0.709\end{array}$ & $\begin{array}{r}{[5,] \quad 4} \\
-4.67 \\
0.01\end{array}$ & $\begin{array}{ll}{[5,] \quad 4} \\
\\
4.71 \\
0.0100\end{array}$ \\
\hline $\begin{array}{l}{[6,]^{5}} \\
0.2596 \\
0.719\end{array}$ & $\begin{array}{l}{[6,] 5} \\
{ }^{2} \\
4.23 \\
0.01\end{array}$ & $\begin{array}{ll}{[6,]} & 5 \\
& - \\
4.27 & \\
0.0100\end{array}$ \\
\hline $\begin{array}{l}{\left[7,{ }^{6} 6\right.} \\
0.2852 \\
0.726\end{array}$ & $\begin{array}{r}{[7,] \quad 6} \\
-3.93 \\
0.01\end{array}$ & 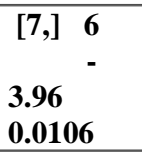 \\
\hline $\begin{array}{l}{[8,7} \\
0.2958 \\
0.729\end{array}$ & $\begin{array}{c}8,] \quad 7 \\
-3.82 \\
0.01\end{array}$ & 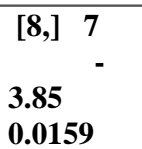 \\
\hline $\begin{array}{l}{[9,]^{8} 8} \\
0.2941 \\
0.729\end{array}$ & $\begin{array}{c}{[9,] 8} \\
{ }^{-} \\
3.85 \\
0.01\end{array}$ & $\begin{array}{l}{[9,]} \\
8 \\
-3.88 \\
0.0145\end{array}$ \\
\hline
\end{tabular}

Table 1 shows that the values of $p$-value are greater than $5 \%$, so we cannot reject the null hypothesis that there is a root alone in the time series, that is mean, the time series is unstable. 
Test the existence of a Autocorrelation between the errors of the series of the Iraqi dinar against the US dollar

Box-Ljung test according to Equation (13) The results as built in Table (2)

Table (2) shows the value of the Q-Stat test in the Iraqi dinar price series against the US dollar

\begin{tabular}{|l|l|}
\hline Box-Ljung test & Box-Ljung test \\
& \\
\hline data: residual & data: residual $^{\wedge} 2$ \\
\hline $\begin{array}{l}\text { X-squared }=59299, \mathrm{df}= \\
\text { 40, p-value }<2.2 \mathrm{e}-16\end{array}$ & $\begin{array}{l}\mathrm{X} \text {-squared }=57562, \mathrm{df}= \\
40, \text { p-value }<2.2 \mathrm{e}-16\end{array}$ \\
\hline
\end{tabular}

As shown in table (2), the correlations of the selfcorrelations according to $\mathrm{Q}$ and $\mathrm{p}$-value values less than $5 \%$ indicate that there is a significant correlation between the errors and the absence of homogeneity of the discrepancies of the observed series. U.S. dollar.

\section{Homogeneity of variance test series returns}

For the purpose of detecting the stability returns a string variation was calculated ARCH Test and referred to in the theoretical side of the equation (15) The test results as shown in Table 3.

Table 3 shows the test to see arch and determine the homogeneity of variances for a series of Iraqi dinar rate against the US dollar

ARCH LM-test; Null hypothesis: no ARCH effects

data: residual

Chi-squared $=2524.5, \mathrm{df}=12, \mathrm{p}$-value $<2.2 \mathrm{e}-16$

From Table (3) we note that the value of p-value is less than $5 \%$ where we can't reject the null hypothesis that provides homogeneity of discrepancies of the original data series
Series Returns: returns were awarded a series by taking the first difference of natural logarithm data series exchange rates of the Iraqi dinar against the US dollar and in the daily summary below some measures series returns.

Table 4 shows some statistics about the series returns

\begin{tabular}{|c|c|}
\hline Min.; & 1st Qu.; Median; Mean; 3rd Qu. Max. \\
\hline$-1.432 \mathrm{e}-0$ & $\begin{array}{ccccc}-9.324 \mathrm{e}-05 & 0.0 & 5.290 \mathrm{e}-06 & 0.00 & 3.639 \mathrm{e}-02\end{array}$ \\
\hline \multicolumn{2}{|c|}{ Jarque Bera Test } \\
\hline \multicolumn{2}{|c|}{ data: return series } \\
\hline $\mathrm{X}$-squared & $=73341, \mathrm{df}=2, \mathrm{p}$-value $<2.2 \mathrm{e}-16$ \\
\hline
\end{tabular}

Is evident from the above indicators calculated that the smallest value in the revenue chain was ($1.432 \mathrm{e}-02)$ and the largest value was $(3.639 \mathrm{e}-02)$ and that the average time series equal to $5.290 \mathrm{e}-$ 06)), and calculable (Jarque-Bera) which indicates That these residues do not follow the law of natural distribution at a significant level $(5 \%)$. Can be illustrated by the graph of the series returns, as shown in Figure (2)

Figure (2) shows the series of returns of the Iraqi dinar exchange rate against the dollar for the period 20102018

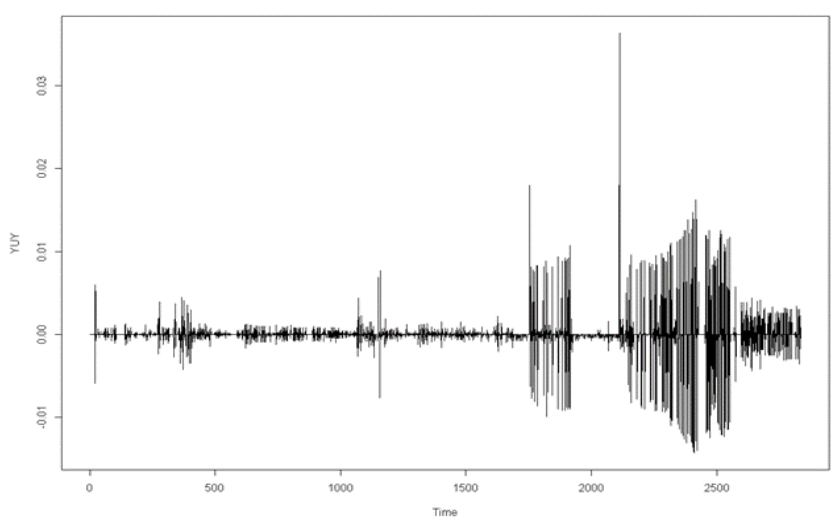

We note from the figure above that the string contains periods of volatility followed by periods of relative stagnation in the twists and turns, and so as we proceed in time. 
Table 5 shows Dickey Fuller test developer to test the stability of returns series

\begin{tabular}{|c|c|c|c|c|c|c|}
\hline \multicolumn{7}{|c|}{ Augmented Dickey-Fuller Test } \\
\hline \multicolumn{7}{|c|}{ alternative: stationary } \\
\hline \multicolumn{3}{|c|}{$\begin{array}{c}\text { Type 1: no drift no } \\
\text { trend }\end{array}$} & \multicolumn{2}{|c|}{$\begin{array}{l}\text { Type 2: with drift } \\
\text { no trend }\end{array}$} & \multicolumn{2}{|c|}{$\begin{array}{l}\text { Type 3: with drift } \\
\text { and trend }\end{array}$} \\
\hline lag & ADF & p.value & $\begin{array}{r}\text { lag AI } \\
\text { p.valu }\end{array}$ & & lag ADF & p.value \\
\hline $\mathbf{0}$ & -84.3 & 0.01 & $\begin{array}{lll}0 & -84.3\end{array}$ & 0.01 & $\begin{array}{ll}0 & -84.2\end{array}$ & 0.01 \\
\hline 1 & -58.5 & 0.01 & $1 \quad-58.5$ & 0.01 & $1 \quad-58.5$ & 0.01 \\
\hline 2 & -43.9 & 0.01 & $2 \quad-43.9$ & 0.01 & $2-43.9$ & 0.01 \\
\hline 3 & -39.7 & 0.01 & $\begin{array}{ll}3 & -39.7\end{array}$ & 0.01 & $\begin{array}{ll}3 & -39.7\end{array}$ & 0.01 \\
\hline 4 & -35.0 & 0.01 & $4 \quad-35.0$ & 0.01 & $4 \quad-35.0$ & 0.01 \\
\hline 5 & -31.3 & 0.01 & $\begin{array}{ll}5 & -31.3\end{array}$ & 0.01 & $\begin{array}{ll}5 & -31.3\end{array}$ & 0.01 \\
\hline 6 & -27.7 & 0.01 & $6 \quad-27.7$ & 0.01 & $6 \quad-27.7$ & 0.01 \\
\hline 7 & -24.4 & 0.01 & $\begin{array}{ll}7 & -24.4\end{array}$ & 0.01 & $\begin{array}{ll}7 & -24.4\end{array}$ & 0.01 \\
\hline 8 & -21.1 & 0.01 & $\begin{array}{ll}8 & -21.1\end{array}$ & 0.01 & $\begin{array}{ll}8 & -21.1\end{array}$ & 0.01 \\
\hline
\end{tabular}

We note from the above table that the values of p-value less than 5\%, which indicates the rejection of the null hypothesis, which states that the series returns are unstable and this avoids that the predictions are inaccurate to appear.

Table (6) below shows the test $\mathrm{Q}$ as well as the values of $\mathrm{P}$-Value of less than $5 \%$, indicating a significant self-correlation between the residuals, which confirms the existence of homogeneity of errors of the chain of returns shown by the boxLjung test

Table 6 shows the effect of the test box-Ljung in a series of price returns of the dinar against the US dollar values

\begin{tabular}{|l|l|}
\hline Box-Ljung test & Box-Ljung test \\
\hline data: Residual & $\begin{array}{l}\text { data: residual } \\
\text { squared }\end{array}$ \\
\hline $\begin{array}{l}\square \text {-squared }=784.17, \mathrm{df}= \\
40, \mathrm{p} \text {-value }<2.2 \mathrm{e}-16\end{array}$ & $\begin{array}{l}\square \text {-squared }=1653.9, \\
\mathrm{df}=40, \mathrm{p} \text {-value }< \\
2.2 \mathrm{e}-16\end{array}$ \\
\hline
\end{tabular}

\section{Homogeneity of variance test series returns}

For the purpose of detecting the stability returns a string variation was calculated multiplier test Lagrange (ARCH Test) and referred to in the theoretical side of the equation (15) The test results as shown in Table 6 .

Table (7) shows the arch test to determine and determine the homogeneity of the variances of the series of returns of the Iraqi dinar against the US dollar

\begin{tabular}{|c|c|c|}
\hline \multicolumn{3}{|c|}{ Lagrange-Multiplier test: } \\
\hline order & LM & p.value \\
\hline$[1]$, & 46436 & $\mathbf{0}$ \\
\hline$[2]$, & 82096 & $\mathbf{0}$ \\
\hline$[3]$, & 121341 & $\mathbf{0}$ \\
\hline$[4]$, & 16923 & $\mathbf{0}$ \\
\hline$[5]$, & 20730 & $\mathbf{0}$ \\
\hline$[6]$, & 24602 & $\mathbf{0}$ \\
\hline
\end{tabular}

Table No. (7) Note that the values of p-value less than $5 \%$ for more than one shift where I reject the null hypothesis which states that the homogeneity of variances series returns and accept alternative hypothesis which provides an impact for $\mathrm{ARCH}$ in returns string data.

\section{Estimation:}

At this stage, the parameters of the studied models (GARCH, TGARCH, EGARCH, ARMAGARCH) are estimated for the purpose of determining the best model for forecasting the Iraqi dinar price series against the US dollar using the greatest possible method.

\section{Estimation of the GARCH model}

\begin{tabular}{|l|r|r|r|r|}
\hline M OLEL & TGARCH $(1,1)$ & TGARCH $(1,2)$ & TGARCH $(2,1)$ & TGARCH $(2,2)$ \\
\hline Estimate & -0.000019 & -0.000015 & -0.000013 & -0.000027 \\
\hline$\Omega$ & 0 & 0 & 0 & 0 \\
\hline 01 & 0.052333 & 0.051286 & 0.026413 & 0.025701 \\
\hline 02 & & & 0.024866 & 0.02506 \\
\hline$Y 1$ & 0.032921 & 0.085427 & -0.02668 & -0.000957 \\
\hline$Y 2$ & & & 0.056003 & 0.088272 \\
\hline$\beta 1$ & 0.907894 & 0.442637 & 0.911187 & 0.440264 \\
\hline$\beta 2$ & & 0.438672 & & 0.440877 \\
\hline$A I C$ & -11.009 & -11.014 & -10.985 & -11.003 \\
\hline BIC & -10.999 & -11.001 & -10.97 & -10.987 \\
\hline H-QIC & -11.006 & -11.01 & -10.98 & -10.997 \\
\hline
\end{tabular}

By studying the functions of self-correlation and partial depending on the tests used in the diagnosis of the degree of the specimen described in the preceding paragraphs could be four models diagnosed as shown in Table 8 was used model GARCH was estimated models described parameters and calculating the criteria for selection of the specimen is best as shown in the table (8) 
Table (8) shows the studied GARCH models and the normal distribution of errors is classified according to the criterion of choice of the best model.

\begin{tabular}{|c|c|c|c|c|}
\hline MOLEL & & & & \\
\hline Estimate & $\operatorname{GARCH}(1,1)$ & $\operatorname{GARCH}(1,2)$ & $\operatorname{GARCH}(2,1)$ & $\operatorname{GARCH}(2,2)$ \\
\hline$\mu$ & -0.000015 & -0.000014 & -0.000009 & 0.000048 \\
\hline $\boldsymbol{\Omega}$ & 0 & 0 & $\mathbf{0}$ & 0 \\
\hline$\alpha 1$ & 0.067387 & 0.078758 & 0.031976 & 0.049032 \\
\hline$\alpha 2$ & & & 0.028076 & $\mathbf{0 . 0 3 3 7 0 7}$ \\
\hline$\beta 1$ & 0.912577 & 0.453834 & 0.916645 & 0.471176 \\
\hline$\beta 2$ & & 0.439405 & & 0.430349 \\
\hline AIC & -11.025 & -11.008 & -10.986 & -10.998 \\
\hline BIC & -11.017 & -10.998 & -10.975 & -10.985 \\
\hline H-QIC & -11.022 & -11.005 & -10.982 & -10.993 \\
\hline
\end{tabular}

From Table (8) we find that the best model according to the selection criteria of AIC, SIC, H-QIC is GARCH (1.1). The estimated equation is:

$\mathbf{y}_{\mathrm{t}}=$

$-0.00002+\sqrt{0.0674 x_{t-1}^{2}+0.9126 \sigma_{t-1}^{2}}$

$* \varepsilon_{\mathrm{t}}$

\section{Estimation of the TGARCH model}

The TGARCH model was applied to the four sample models described above. Model parameters were estimated and the criteria for selecting the best model were calculated. As shown in Table 9.

Table (9) shows the TGARCH models studied and the normal distribution of errors is determined according to the criterion of choice of the best model.

From Table (9) we find that the best model studied in GARCH-M models will be TGARCH $(1,2)$ according to AIC, SIC, H-QIC selection criteria.

$\mathbf{y}_{\mathrm{t}}=$

$-0.00002+$

$\sqrt{\left(0.0513+0.0854 d_{t-i}\right) x_{t-i}^{2}+0.4426 \sigma_{t-1}^{2}+0.43}$ $* \varepsilon_{\mathrm{t}}$

\section{Estimation of the EGARCH model}

Table (10) shows that the best model estimated in the EGARCH models applied according to the appropriate model selection criteria is EGARCH (2.2), which can be written as follows:

$\mathbf{y}_{\mathrm{t}}$ $=-0.000002+$

$\sqrt{e^{-1.1754+0.994 \ln \left(\sigma_{t-j}^{2}\right)+0.0241\left\{\left|\frac{x_{t-i}}{\sigma_{t-i}}\right|-\sqrt{\frac{2}{\pi}}\right\}-0.1197\left\{\left|\frac{x_{t-i}}{\sigma_{t-i}}\right|-\sqrt{\frac{2}{\pi}}\right\}+0.2611 \frac{x_{t-1}}{\sigma_{t-1}}+0.3478 \frac{x_{t-2}}{\sigma_{t-2}}}}$ $* \varepsilon_{\mathrm{t}}$
Table (10) shows the studied

EGARCH models, and the normal distribution of errors is classified according to the criterion of choice of the best model

\begin{tabular}{|c|c|c|c|c|}
\hline MOLEL & \multirow{2}{*}{$\operatorname{EGARCH}(1,1)$} & \multirow{2}{*}{$\operatorname{EGARCH}(1,2)$} & \multirow{2}{*}{$\operatorname{EGARCH}(2,1)$} & \multirow{2}{*}{ EGARCH(2,2) } \\
\hline Estimate & & & & \\
\hline$\mu$ & -0.000002 & -0.00006 & -0.000005 & -0.000002 \\
\hline$\Omega$ & -1.194879 & -0.059614 & -1.171493 & -1.175397 \\
\hline$\alpha 1$ & 0.061135 & -0.204231 & 0.127602 & 0.024047 \\
\hline$\alpha 2$ & & & -0.164868 & -0.11967 \\
\hline$\lambda 1$ & 0.494138 & 0.041791 & 0.271619 & 0.261054 \\
\hline$\lambda 2$ & & & 0.28956 & 0.347751 \\
\hline$\beta 1$ & 0.900554 & 1 & 0.900745 & 0.449306 \\
\hline$\beta 2$ & & -0.006076 & & 0.45087 \\
\hline AIC & -10.313 & -10.256 & -10.334 & -10.476 \\
\hline B IC & -10.303 & -10.243 & -10.32 & -10.459 \\
\hline H-QIC & -10.309 & -10.251 & -10.329 & -10.47 \\
\hline
\end{tabular}

\section{Estimation of the ARMA-GARCH} model

The ARMA-GARCH model has been applied to the scores of the four previously diagnosed models, model parameters have been estimated and the criteria for selecting the best model have been calculated. As shown in Table 11,

Table (11) shows the studied ARMAGARCH models, which have the normal distribution of errors

\begin{tabular}{|l|c|c|c|c|}
\hline MOLEL & \multirow{2}{*}{ ARMA(0,1)- } & ARMA(0,1)- & ARMA(0,1)- & ARMA(0,1)- \\
\cline { 1 - 4 } Estimate & GARCH(1,1) & GARCH(1,2) & GARCH(2,1) & GARCH(2,2) \\
\hline ma & -0.637184 & -0.638666 & -0.63795 & -0.6397 \\
\hline$\Omega$ & 0 & 0 & 0 & 0 \\
\hline$\alpha 1$ & 0.050525 & 0.050367 & 0.025117 & 0.025 \\
\hline$\alpha 2$ & & & 0.025077 & 0.025 \\
\hline$\beta 1$ & 0.901086 & 0.449921 & 0.900758 & 0.45 \\
\hline$\beta 2$ & & 0.450173 & & 0.45 \\
\hline AIC & -10.975 & -11.048 & -10.957 & -11.028 \\
\hline BIC & -10.967 & -11.038 & -10.947 & -11.016 \\
\hline H-QIC & -10.972 & -11.045 & -10.954 & -11.024 \\
\hline
\end{tabular}

From Table (11) we observe that the best model chosen is the ARMA $(0,1)-G A R C H(1,2)$ model according to the criteria for selecting the best model and its estimated equivalent as shown below:

$\mathbf{y}_{\mathrm{t}}=$

$-0.6387 x_{t-1}+$

$\sqrt{(0.0504) \mathrm{x}_{\mathrm{t}-1}^{2}+0.45 \sigma_{t-1}^{2}+0.45 \sigma_{t-2}^{2}} * \varepsilon_{\mathrm{t}}$ 
And to choose the best model for the series of returns of exchange rates of the Iraqi dinar against the US dollar for the period 2010 to 2018 by comparing the estimated models as shown in table (12)

Table (12) shows the best GARCH family models that have been adopted and the normal distribution of errors is classified according to the criterion of choice of the best model.

\begin{tabular}{|c|c|c|c|c|}
\hline MOLEL & \multirow{2}{*}{$\operatorname{GARCH}(\mathbf{1}, \mathbf{1})$} & \multirow{2}{*}{$\operatorname{TGARCH}(1,2)$} & \multirow{2}{*}{$\operatorname{EGARCH}(2,2)$} & \multirow{2}{*}{$\begin{array}{l}\operatorname{ARMA}(0,1)- \\
\operatorname{GARCH}(1,2)\end{array}$} \\
\hline Estimate & & & & \\
\hline$\mu$ & -0.000015 & -0.000015 & -0.000002 & -0.638666 \\
\hline$\Omega$ & 0 & $\mathbf{0}$ & -1.175397 & 0 \\
\hline$\alpha 1$ & 0.067387 & 0.051286 & 0.024047 & 0.050367 \\
\hline$\alpha 2$ & & & -0.11967 & \\
\hline r1 & & 0.085427 & 0.261054 & \\
\hline $\mathrm{r} 2$ & & & 0.347751 & \\
\hline$\beta 1$ & 0.912577 & 0.442637 & 0.449306 & 0.449921 \\
\hline$\beta 2$ & & 0.438672 & $\mathbf{0 . 4 5 0 8 7}$ & 0.450173 \\
\hline AIC & -11.025 & -11.014 & -10.476 & -11.048 \\
\hline BIC & -11.017 & -11.001 & -10.459 & -11.038 \\
\hline H-QIC & -11.022 & -11.01 & -10.47 & -11.045 \\
\hline
\end{tabular}

From Table (11), the ARMA-GARCH model is superior to the other models. The best model of the proposed models is ARMA $(0,1)-\mathrm{GARCH}$ $(1,2)$ according to the selection criteria of AIC, SIC, H-QIC

\section{Check the appropriate model}

After diagnosing the model, determining its grade and estimating its parameters for a series of price returns, the model's efficiency and accuracy in interpreting the behavior of the time series should be ascertained. This is done by the Test and Box-Ljung for standard and standard square

Table 13 shows the arch-test of the gears

\begin{tabular}{|c|c|}
\hline \multicolumn{2}{|c|}{ Weighted ARCH LM Tests } \\
\hline Statistic & P-Value \\
\hline ARCH Lag[4] 0.001832 & 0.9659 \\
\hline ARCH Lag[6] 0.003999 & 0.9999 \\
\hline ARCH Lag[8] 0.004658 & 1.0000 \\
\hline
\end{tabular}

Note from the table above that the value of $\mathrm{p}$ value is greater than $5 \%$. We can't reject the null hypothesis that the errors are homogeneous
Table (14) shows the Box-Ljung test to detect random errors of standard random square error errors

\section{Weighted Ljung-Box Test on Standardized} Residuals

\begin{tabular}{|c|c|c|}
\hline \multicolumn{3}{|c|}{ statistic p-value } \\
\hline Lag[1] & 10.25 & $1.365 \mathrm{e}-03$ \\
\hline $\operatorname{Lag}[2 *(p+q)+(p+q)-1][2]$ & 10.25 & $6.829 \mathrm{e}-10$ \\
\hline $\operatorname{Lag}[4 *(p+q)+(p+q)-1][5]$ & 11.48 & $2.434 \mathrm{e}-04$ \\
\hline \multicolumn{3}{|l|}{ d.o.f $=1$} \\
\hline \multicolumn{3}{|l|}{ H0 : No serial correlation } \\
\hline \multicolumn{3}{|c|}{$\begin{array}{l}\text { Weighted Ljung-Box Test on Standardized Squared } \\
\text { Residuals }\end{array}$} \\
\hline & statistic & p-value \\
\hline Lag[1] & 0.001033 & 0.9744 \\
\hline $\operatorname{Lag}[2 *(p+q)+(p+q)-1][8]$ & 0.005800 & 1.0000 \\
\hline $\operatorname{Lag}[4 *(p+q)+(p+q)-1][14]$ & 0.010925 & 1.0000 \\
\hline d.o.f $=3$ & & \\
\hline
\end{tabular}

Note that the standard errors in the displacements $(1,4,6)$ mean that the standard errors are not normal distributed. Note that the standard error boxes are not significant in the displacements $(1,4,6)$. This means that the standard errors are distributed naturally

Figure 3 illustrates the prediction of the values of the series returns and confidence limits for those predictions and the estimated variation

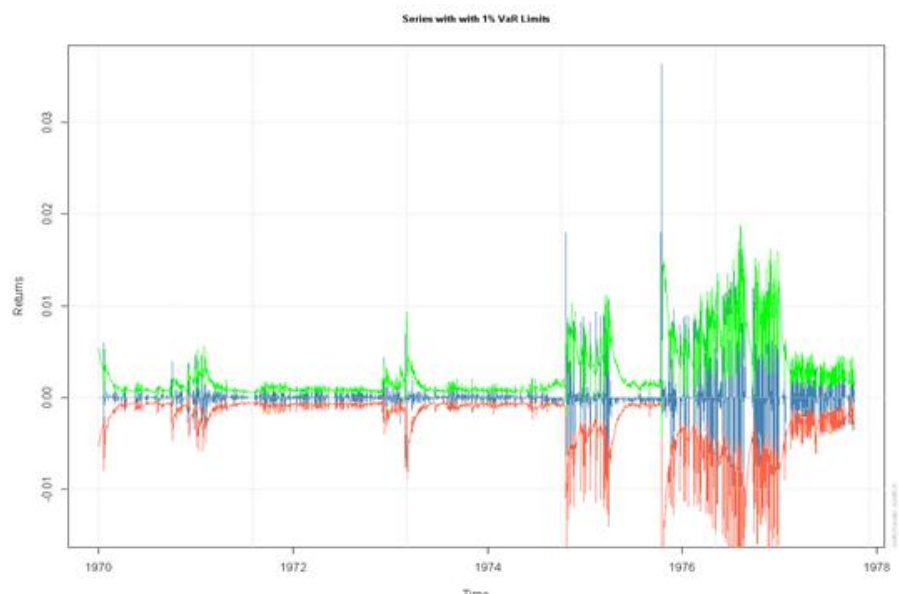

We note from Figure (3) confidence limits for the values of the real and predictive values of the series returns, as well as the estimated variance. 
Table (15) shows a comparison between the ARMA-GARCH and GARCH model according to the criterion of choice of the best model

\begin{tabular}{|l|l|l|}
\hline MODEL & RMSE & MAE \\
\hline $\begin{array}{l}\text { ARMA (0,1)-GARCH } \\
(\mathbf{2 , 1})\end{array}$ & $\mathbf{0 . 0 0 0 6 3 5 5 3 5 3}$ & $\mathbf{0 . 0 0 0 3 2 5 8 1 7 9}$ \\
\hline GARCH (1, $)$ & $\mathbf{0 . 0 0 0 6 5 6 0 9 5 3}$ & $\mathbf{0 . 0 0 0 2 8 6 5 4 9 5}$ \\
\hline
\end{tabular}

We note from the above table as well as superior specimen ARMA-GARCH on the specimen by GARCH standards (MAE, RMS, ) and this in turn suggests that the specimen ARMA $(0,1)$ GARCH $(2,1)$ flour to a large extent and is therefore the best specimen to predict prices Exchange of the Iraqi dinar against the US dollar. The GARCH $(1,1)$ model was chosen for comparison because it is very close to the ARMA model (0.1) -GARCH (2.1) according to the criteria for model selection (AIC, SIC, H-QIC).

\section{Conclusions and recommendations Conclusions}

1 - The exchange rate of the Iraqi dinar against the US dollar was unstable in the middle and contrast.

2. The series returns have turned stable chain in the center by Dickey Fuller test.

3. The series returns are unstable by arch test contains a serial link (moral links).

4. The best model is the ARMA (0-1) -GARCH (2.1) model, which is superior to the other models studied according to AIC, SIC, H-Q

5. The selected model is superior to RMSE, MAE, compared with GARCH $(1,1)$.

6 . The models of autoregression conditional on heterogeneity of variance are more efficient in predicting fluctuations.

\section{Recommendations}

1. Use other models for comparison such as models, GARCH-M IGARCH, NGARCH

2. Use other methods to estimate model parameters such as QMLE.

3. Using the GARCH family models to predict other financial time series to estimate and study the behavior of these strings because they have the ability to explain the behavior of these strings characterized by heterogeneity of variance.

\section{References:}

1. Banumathy, K. and R. Azhagaiah, Modelling stock market volatility: Evidence from India. Managing Global Transitions, 2015. 13(1): p. 27.

2. Engle, R.F., D.M. Lilien, and R.P. Robins, Estimating time varying risk premia in the term structure: The ARCH-M model. Econometrica: Journal of the Econometric Society, 1987: p. 391-407.

3. Falk, M., et al., A first course on time series analysis: examples with SAS. 2006.

4. Francq, C. and J.-M. Zakoian, GARCH models: structure, statistical inference and financial applications. 2011: John Wiley \& Sons.

5. Lütkepohl, H. and M. Krätzig, Applied time series econometrics. 2004: Cambridge university press.

6. Malik, V., ARIMA/GARCH (1, 1) MODELLING AND FORECASTING FOR A GE STOCK PRICE USING R.

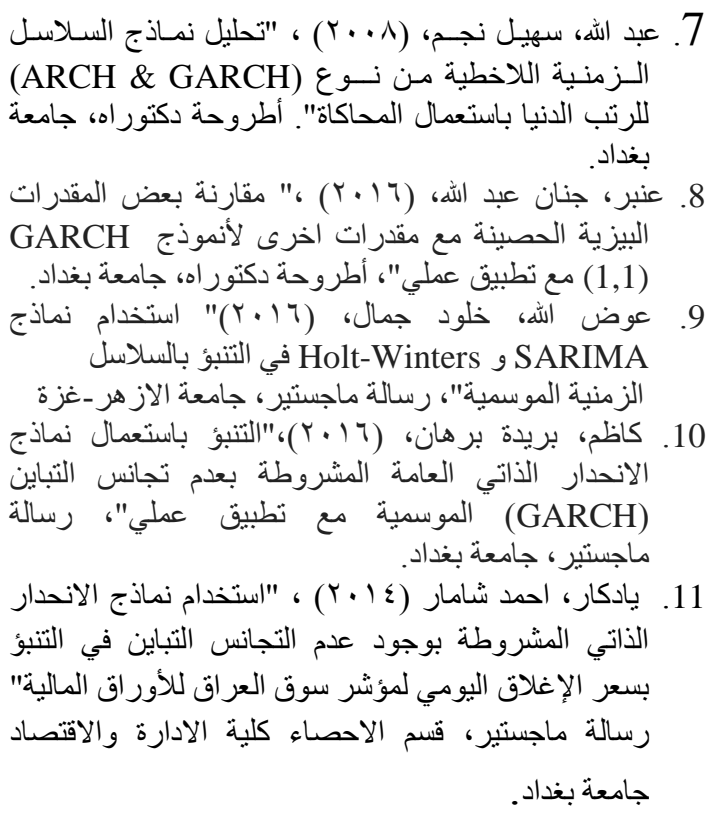




\title{
التنبؤ بأسعار سعر الصرف للاينار العراقي مقابل الدولار الامريكي باستعمال صيغ

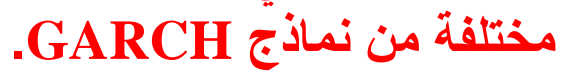

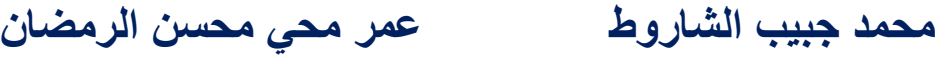 \\ كلية الإدارة والاقتصاد / جامعة القادسية
}

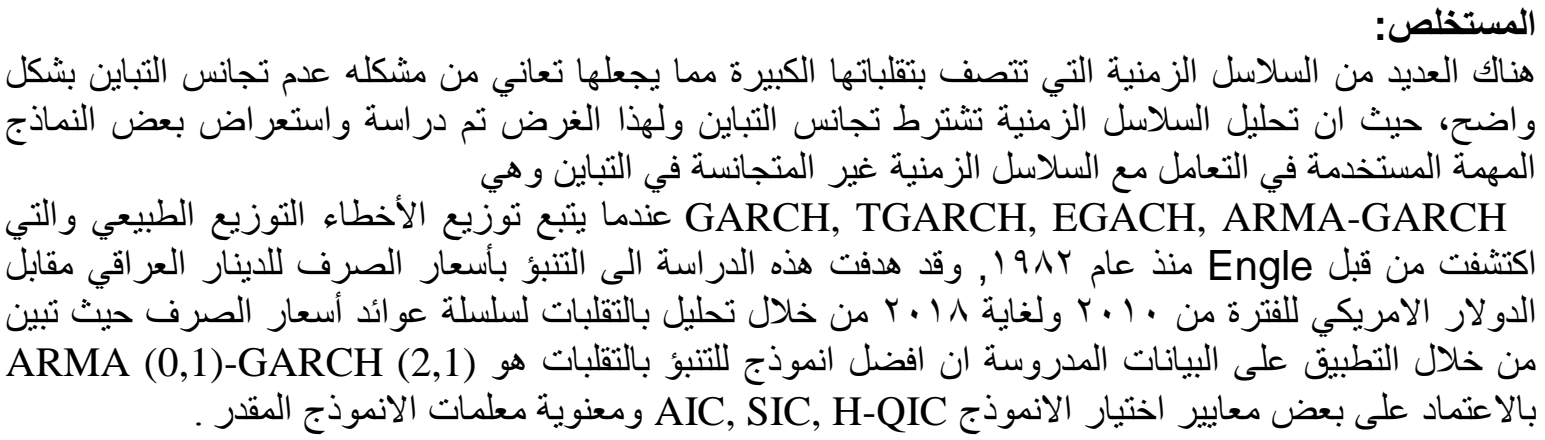

